\title{
Cardiovascular magnetic resonance myocardial feature tracking for the measurement of myocardial twist and untwist at rest and during dobutamine stress in healthy volunteers
}

\author{
Pablo Lamata ${ }^{1,7}$, Shazia T Hussain ${ }^{2}$, Shelby Kutty ${ }^{3}$, Michael Steinmetz ${ }^{4}$, Jan M Sohns ${ }^{5}$, Martin Fasshauer ${ }^{5}$, \\ Wieland Staab ${ }^{5}$, Christina Unterberg-Buchwald ${ }^{5,6}$, Joachim Lotz ${ }^{5}$, Andreas Schuster ${ }^{6^{*}}$
}

From 17th Annual SCMR Scientific Sessions

New Orleans, LA, USA. 16-19 January 2014

\section{Background}

CMR feature tracking (CMR-FT) is a method of assessing strain from routinely acquired steady- state free precession (SSFP) cine images similar to echocardiographic speckle tracking. However, its application to determine myocardial twist and untwist has never previously been explored. We sought to determine the feasibility of measuring twist and untwist from routine cine images in healthy volunteers at rest and during inotropic stimulation.

\section{Methods}

Ten healthy volunteers had routine SSFP cine images acquired at rest and after inotropic stimulation (10 and 20 micrograms of dobutamine). The rotation of the basal and apical slices, both subendocardial and subepicardial, was measured and global LV twist $\theta$ was calculated as the difference between the counter-clockwise (positive) rotation at the apex ( $\phi$ apex) and clockwise rotation at the base (viewed from apex), $\theta=\phi$ apex- $\phi$ base. Peak twist and untwist-rate and the respective times to peak were calculated using MATLAB software for both the subepicardial and subendocardial layers and compared between rest and stress.

\section{Results}

The peak and time to peak myocardial twist and untwist-rate are displayed at the endocardial (Table 1) and epicardial levels (Table 2). Twist and untwist-rate significantly increased with faster time to peak during dobutamine stimulation at the endocardial level $(\mathrm{p}<0.05$, significance measured with a paired $\mathrm{t}$-test after logarithmic transformation of the sample). These changes were paralleled by a trend towards increased twist at the epicardial

Table 1 Mean values of peak and time to peak twist and untwist-rate at the endocardial level.

\begin{tabular}{ccccc}
\hline Mean \pm SD & Peak twist endocardial (degrees) & $\begin{array}{c}\text { Time to peak } \\
\text { twist (ms) }\end{array}$ & $\begin{array}{c}\text { Peak untwist-rate } \\
\text { endocardial (degrees/s) }\end{array}$ & $\begin{array}{c}\text { Time to peak } \\
\text { untwist-rate }(\mathbf{m s})\end{array}$ \\
\hline Volunteers at rest & $17 \pm 11$ & $393 \pm 180$ & $-140 \pm 58$ & $495 \pm 194$ \\
\hline $\begin{array}{c}\text { Volunteers at 10 mcg of } \\
\text { dobutamine }\end{array}$ & $26 \pm 7$ & $247 \pm 49$ & $-282 \pm 100$ & $342 \pm 56$ \\
$(p=0.03)$ & $(p=0.007)$ & $-3501)$ & $(p=0.03)$ \\
\hline $\begin{array}{c}\text { Volunteers at 20 mcg of } \\
\text { dobutamine }\end{array}$ & $30 \pm 15(p=0.001)$ & $238 \pm 54$ & $-356 \pm 179$ & $324 \pm 57$ \\
$(p=0.005)$ & $(p=0.003)$ & $0.01)$ & $(p=01)$ \\
\hline
\end{tabular}

${ }^{6}$ Department of Cardiology and Pneumology and German Centre for

Cardiovascular Research, Georg-August-University, Göttingen, Germany

Full list of author information is available at the end of the article 
Table 2 Mean values of peak and time to peak twist and untwist-rate at the epicardial level

\begin{tabular}{ccccc}
\hline $\begin{array}{c}\text { Mean } \pm \text { Standard } \\
\text { Deviation }\end{array}$ & $\begin{array}{c}\text { Peak twist epicardial } \\
\text { (degrees) }\end{array}$ & $\begin{array}{c}\text { Time to peak } \\
\text { twist (ms) }\end{array}$ & $\begin{array}{c}\text { Peak untwist-rate epicardial } \\
\text { (degrees/s) }\end{array}$ & $\begin{array}{c}\text { Time to peak } \\
\text { untwist-rate (ms) }\end{array}$ \\
\hline Volunteers at rest & $12 \pm 9$ & $325 \pm 106$ & $-119 \pm 57$ & $449 \pm 91$ \\
\hline $\begin{array}{c}\text { Volunteers at 10 mcg of } \\
\text { dobutamine }\end{array}$ & $17 \pm 8$ & $257 \pm 65$ & $-157 \pm 78$ & $366 \pm 78$ \\
$(p=0.09)$ & $(p=0.03)$ & $-226 \pm 110$ & $(p=0.03)$ \\
\hline $\begin{array}{c}\text { Volunteers at 20 mcg of } \\
\text { dobutamine }\end{array}$ & $18 \pm 11$ & $204 \pm 72$ & $277 \pm 82$ \\
$(p=0.14)$ & $(p=0.08)$ & $0.03)$ & $0.03)$ \\
\hline
\end{tabular}

level and significantly increased untwist-rate associated with faster time to peak twist and untwist-rate during dobutamine stimulation (table 2).

\section{Conclusions}

It is feasible to derive myocardial twist and untwist and respective times to peak, both at rest and dobutamine stress using CMR-FT. Application of these new measures of deformation by CMR-FT should next be explored in disease states.

\section{Funding}

German Centre for Cardiovascular Research (DZHK Partner Site Göttingen).

\section{Authors' details}

'Department of Computer Science, University of Oxford, Oxford, UK. ${ }^{2}$ Papworth Hospital NHS Trust, Papworth Everard, Cambridgeshire, UK. ${ }^{3}$ Children's Hospital and Medical Center, University of Nebraska College of Medicine, Omaha, Nebraska, USA. ${ }^{4}$ Department of Pediatric Cardiology and Intensive Care Medicine and Heart Research Center, Georg-August-University, Göttingen, Germany. ${ }^{5}$ Institute for Diagnostic and Interventional Radiology, Georg-August-University, Göttingen, Germany. ${ }^{6}$ Department of Cardiology and Pneumology and German Centre for Cardiovascular Research, GeorgAugust-University, Göttingen, Germany. ${ }^{7}$ Dept. of Biomedical Engineering, St Thomas' Hospital, King's College, London, UK.

Published: 16 January 2014

- Convenient online submission

- Thorough peer review

- No space constraints or color figure charges

- Immediate publication on acceptance

- Inclusion in PubMed, CAS, Scopus and Google Scholar

- Research which is freely available for redistribution 